\title{
ORGANISATIONAL PATHOLOGIES UNDER CONDITIONS OF ECONOMIC DOWNSWING
}

\author{
Jacek Pasieczny \\ Faculty of Management, University of Warsaw, Poland, jpasieczny@wz.uw.edu.pl
}

\begin{abstract}
The topic of organisational pathology is surprisingly absent in literature on management, especially when bearing in mind the theoretical and practical import of such questions. The intention of the author is to fill in this gap, at least partially. The paper is based on an analysis of literature and an empirical research conducted by the author. The research applied partially structured interviews as its method. These interviews were conducted with entrepreneurs and managers of various levels. They made possible the drawing of conclusions relating to conditions behind the genesis and growth of selected organisational pathologies in a situation of economic downswing. The article briefly presents the concept and influence of pathology on the functioning of an organisation. The author concentrates on the causes of the phenomenon and presents them from various perspectives. It is during times of economic downswing that an increase in unethical behaviour, including corruption, mobbing as well as others, becomes particularly visible. Also noticeable is concentrating on limiting costs, which can sometimes reach pathological scale. This can lead to a permanent loss of pro-development potential by the organisation. Moreover, numerous pathological phenomena emerge at the tangent point of the organisation and its surroundings. The source of many undesirable phenomena in the organisation and in its relations with its surroundings is a fall in trust, which makes its appearance in crisis situations. More often than not, managers facing a situation in which they have no choice perpetuate organisational pathologies, whilst, at the same time, being aware of the lack of validity of their actions. However, a more frequent source of problems is the differences in perspective in perceiving organisational phenomena by various actors and stakeholders.
\end{abstract}

Keywords: organisational pathologies, downswing, dysfunction, error

JEL Classification: M 10

\section{Introduction}

Pathologies, understood as irregularities, inseparably accompany all of man's activities. This also pertains to management. Actually, it is difficult to look at management as organised action without making reference to pathologies. In fact, numerous authors have undertaken the question of pathology whilst analysing other matters. However, identification and descriptions of pathologies have rarely been the primary goal of researchers. It is for this reason that analysis of literature fails to give significant pointers relating to the methodological aspects of conducting research in this area. The sensitive nature of this research area is undoubtedly an impediment to the process of procuring information. Many respondents, for various reasons, declined participation in such a study. What is of great importance in this case is the open and honest expression of opinions by those questioned. It is for this reason that this study has applied partially structured interviews. Only such an approach can lead to the emergence of an 'open catalogue of organisational pathologies'.

The sources of organisational pathologies as well as areas in which they originate are diverse. However, it is possible to identify certain regularities. The goal of this paper is to present selected pathologies in the organisation and the management process, with special stress on conditions of economic downswing. This text is based on the analysis of literature as well as partially structured interviews conducted amongst deliberately selected entrepreneurs, specialists and managers of various levels. The basis for the writing of this paper was the 'Managerial Errors' research programme as undertaken at the Faculty of Management of the University of Warsaw over the years 2012-2016. The research was interpretative in character. It made it possible to identify selected pathologies and procure diverse opinions regarding their areas and causes. 


\section{The Essence and Elements of the Theory of Pathology}

The word pathology is derived from the Greek language and means a state of being ill or the study of illnesses. In common usage, pathology is understood as the extended presence of a significant irregularity.

In as much as pathology is the study of illness, organisational pathology can be treated as the study of 'organisational disease'. Looking at the second meaning of the phrase, organisational pathology is a long-term, significant irregularity in the functioning of an organisation. According to Kieżun (1971), the study of organisational pathology can be considered as a clearly isolated part of the theory of organisation and management, which is concerned with the analysis of deviations and their subsequent generalisation as well as the defining of remedial measures. As to organisational pathology itself, that same author defines it as a 'relatively permanent irregularity responsible for waste in an economic sense and (or) moral one exceeding the limits of social tolerance' (Kieżun, 2012). By analogy, management pathology may be defined as significant, long-term irregularity in the process of managing an organisation or as an isolated part of the study of management concerned with the analysis of the functioning of irregularities in management.

A concept that is similar to pathology is dysfunction. Dysfunction should be treated as a phenomenon that has a negative impact on a defined social system. Systems are subject to tension and changes in ill-advised directions as a result of dysfunction. The long-term effect of dysfunction can cause a system to enter a pathological state. This means that dysfunction in an organisation leads to interference in the efficient functioning of that organisation, where management dysfunction makes impossible or impedes proper management of the selected organisational system. However, the borderline between dysfunction and pathology is not always clear, which is reflected in the area of definitions. For example, Albrecht (2003) perceives dysfunctions as organisational disorders. According to Cameron, Whetten and Kim (1987), dysfunctions can include both processes, such as increasing centralisation, and states, such as low morale.

According to Stocki (2005), "pathology encompasses all dysfunction in the organization that does not allow the achievement of realistic goals set for the given organization and aligned with social good, using defined means over a defined time period'. A similar view of pathology ('through dysfunction') was held by many of the interviewed managers and entrepreneurs.

The term organisational inefficiency is also used relatively often. Entire organisational systems or their individual processes are seen as being inefficient. Inefficiency is the opposite of efficiency - the praxeological assessment of 'good work'. The basic positive aspects of efficiency are effectiveness, gainfulness and economy. In a sense, these advantages are gradable. Therefore, organisation or process inefficiency is treated as the holding of an insufficient quantity of the positive aspects of efficiency by the organisation or process. Thus, a significant problem is the establishing of a threshold for the efficiency barrier defining the limits of phenomena deemed as being pathological (Kieżun, 2012). The structure of intended effects of human endeavour as developed by Zielenewski may prove helpful.

Table 1. Structure of the Effect of Action (Source: Kieżun, 2012)

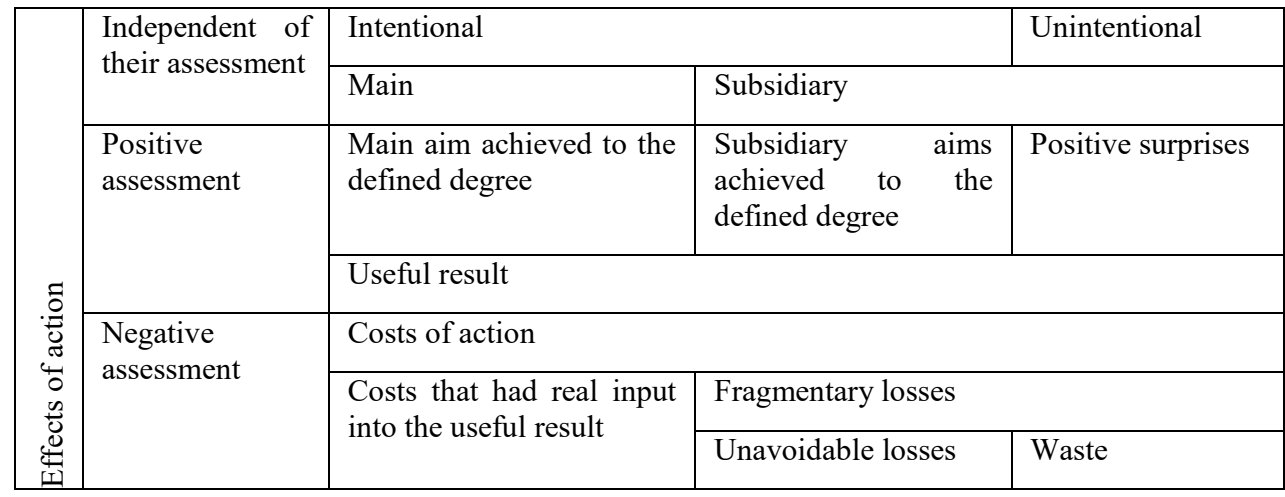


From the point of view of praxeologically efficient action, minimising waste should be a goal. However, it should be borne in mind that there exists a limit of socially acceptable waste. This gives rise to a question: Is all waste pathological or does it only become so when it crosses the limits of social acceptance? Bearing in mind the complexity of the surroundings, especially the variety of legal and cultural conditions, the social acceptance factor seems to be important. However, the matter of recurrence is even more important. One-time waste may be the outcome of a mistake or an error, understood as the performance of an action in an improper manner, an inaccuracy in some product of work or reasoning, but of a unit or random character. Waste that is relatively permanent, the result of recurring action and/or made permanent in a formal manner, becomes pathology. Pathologies, dysfunctions and managerial errors are part of the broader thematic field of mismanagement, which means managing incompetently or dishonestly. Several authors in their papers use this generic term (e.g. Brown and Hesketh, 2004; Heller and Darling, 2011; Petrucelli and Peters, 2017; Christensen, 1993; Webb, 1992). The pathology studies described in this article also fall within this broad spectrum.

Consideration of pathologies has been present in topical literature from almost its very inception. Though not directly, these matters were present in the works of Xenophon as well as the Code of Hammurabi. The entire classical stream of management science can be considered a derivative of the desire by distinguished engineers to eliminate organisational dysfunction and pathology. Later streams of management science also looked into this matter.

Depending on the agreed assumptions, pathologies may be analysed in the context of the ecology of the population of organisations (Scott, 1992), the organisation lifecycle (Samuel, 2013), psychopathology (Kets de Vries and Miller, 1984) or applying a systemic metaphor for the organism (Miller et al., 1991). There is also a wealth of achievement amongst the representatives of the diagnostic approach, which seeks and creates instruments for the identification and analysis of pathology subject to concrete situational conditions (e.g. Launsby, 2016; Gouliemos, 2005). Examples from this group of authors include Stocki (2013), Gestmann (2001), Guy (1989) as well as Robinson and Benett (1995), who created an interesting typology of organisational behaviours outside the norm.

The area of emergence of organisational pathology that is best studied is the social area. Stocki (2011), Lencioni (2005) and Samuel (2010) are amongst those devoting their studies to this field. This group also includes authors analysing various dysfunctions and pathological behaviours. Questions of professional burnout are studied by Awa, Plaumann and Walter (2010); Chan (2011); Halbesleben, Osburn and Mumford (2006); and others. White (2010) considers the source of dysfunction to be excessively detailed management in the actions of managers. Dysfunctions linked to various types of organisational cultures are analysed by Fink, Dauber and Yolles (2012). The question of bullying and intimidation in the workplace is taken up in the works of Archer (1999); Ashforth (1984); Björkvist, Österman and Hjelt-Bäck (1994); Einarsen (2000); and others. It is the view of Lecker (2011) that the sources of unethical leadership may be found in both the professed system of values and the qualities of the worker as well as in organisational conditions such as a high level of expectations on the part of the organisation, high stress levels and forcing appropriate behaviour though hierarchical operation.

Questions of pathology in other areas of the organisation are looked at by researchers less often. However, there are questions that are well studied. Amongst them are pathological phenomena accompanying the processes of decision-making. Perlow, Okhuysen and Repenning (2002) link pathology with a rapid rate of decision-making. Pathological mechanisms of mutual undermining of decisions by members of teams in administrative organisations are noted by Schulman (1989). McMillan and Overall (2016) see the sources of dysfunction in faulty strategic management systems that filter transmitted information, stressing the good and screening out the bad, for example. Other researchers are involved in the study of pathologically extreme economising (Goffnett, Lepisto and Hayes, 2016; Pasieczny, 2005).

Areas subject to study include external sources of pathology. Questions of organisational pathologies during crises are examined by Miller (1998). The role of financial institutions in the origins of crises is stressed by Bogle (2009). Other researchers are studying problems stemming from expectations of very quick organisational action (Perlow, Okhuysen and Repenning, 2002). 
Both research and practice often apply a subdivision into pathologies in the functioning of businesses and administrative pathologies. This subdivision is decidedly hazy. A significant portion of pathologies, or even their decided bulk, is universal in character. Moreover, numerous pathologies occur at the tangent point of the business and public sectors.

The group of universal pathologies most certainly includes what is known as 'negative autonomisation'. It includes (Kieżun, 2012):

- Switching the main objective to subsidiary ones or to another main objective,

- Changes in ways of operating, and

- A change in goals, in which the means of action (indirect goal) becomes the main objective.

Robert K. Merton already observed the so-understood autonomisation in the 1950s. He noted the phenomenon of internalisation of organisational rules that are introduced to achieve concrete organisational goals but become values in and of themselves regardless of the achievement of those goals. Questions of autonomisation by organisational units concentrating exclusively on 'ancillary goals' that are means to achieve the main goals (bypassing other 'ancillary goals' not encompassed by their action) was also a subject of study of the only Nobel Prize winner in the field of organisation and management(Simon, 2007). Simon's efforts mainly concentrated on administration. However, his findings were universal in character. Kieżun (2012) considers the worst pathologies in administration to be

- Gigantomania - permanent increase in the number of employees, multiplication of organisational entities

- Luxurymania - unjustified excessive spending on the external manifestation of power

- Corruption - official misconduct or misuse of public function for personal gain

- Arrogance of power - disrespect of customers by administrative officers

In addition to pathologies in administration, equally painful are pathologies, errors and dysfunction in businesses. In line with research conducted by the author, long-term and permanent errors in management that are a source of organisational pathology include (Pasieczny and Glinka, 2008):

1. The creation of irreplaceable people by the organisation,

2. Replacing day-to-day communication with occasional events/campaigns and the inept communicating of changes,

3. Excessive dependence on procedures,

4. Failure to see ties between organisational outlay and effects,

5. Lack of any will to learn and acquire new knowledge from employees,

6. Shifting the responsibility for mistakes to others,

7. Surrendering to the herd effect,

8. The ignoring of minor signals,

9. Concentration on the symptoms of the problem, not their causes,

10. Shortening the time horizon for decisions,

11. Lack of vision and reactivity, and

12. A quest for novelties and disregard for tested solutions.

\section{Research Conditions and Methodological Limitations}

The inspiration for commencing studies into pathologies was the author's experience in organisational advisory services, which allowed the noting of long-term, serious and recurring problems faced by 
many organisations. These even made their appearance more often than once in organisations applying refined solutions in the area of management. The diagnosing of such problems and identification of their sources is an important task from the point of view of questions of the value of the organisation. Organisational pathologies are a significant factor lowering the value of an organisation. Their elimination may prove a relatively inexpensive (though not always simple) path to increasing such value.

Research into pathologies is impeded because of the already-mentioned unwillingness to disclose the negative sides of the functioning of an organisation. The motive behind this may be a fear of displaying the organisation in an unfavourable light (and thus tarnishing its image) as well as fear of the consequences of being accused of disloyalty.

A significant barrier involves the problem of the interpretation of concepts and variations in the perception of phenomena by those examined. This problem is seen in the execution of both qualitative and quantitative studies.

The research presented in this paper is located in the interpretive paradigm and was conducted using text analysis and partially structured interviews. The aim of the researcher was the creation of an 'open catalogue' of errors, pathologies and dysfunction and, equally importantly, discovering and understanding the mechanisms interfering with the functioning of the organisation. Realistion of a similar goal using 'classical' quantitative methods would have been difficult, if not impossible.

This text is based on the analysis of literature as well as partially structured interviews conducted amongst 22 deliberately selected entrepreneurs, specialists and managers of various levels. A consequence of such a deliberate selection of the sample is lack of representativeness of the study. Six entrepreneurs, 2 highly qualified specialists working in a nonpublic health service entity, 13 company managers and 1 mid level manager from a housing cooperative were interviewed. Amongst the entrepreneurs, micro-entrepreneurs and owners of small businesses made up the majority. Most of the entrepreneurs carry out service activities. Their companies are located in the Polish capital, but because of the wide use of the Internet, their activity is not limited to their location. In spite of the small size of their companies, some are successfully operating on foreign markets. The surveyed entrepreneurs were mainly young people aged 25-35 years. Five of the six entrepreneurs come from families with entrepreneurial traditions. Only one has managerial education. The company from the healthcare industry from which the interviewees come is the largest private company in the industry in Poland. It employs more than 14,000 employees, including 6,000 doctors and has 200 own and 2,500 partners' clinics. The interview was conducted with the company's network development specialists. Both are graduates of management schools. With a single exception, the managers were responsible for organisations or organisational cells in Poland. The majority of the managers were employed in large and medium companies. They included one president of a pumped-storage Power plant, presidents and managers of waterworks in several Polish cities, an airport manager, hypermarket managers and managers of construction companies.

One of the respondents was a high-level manager of a Russian company belonging to an international corporation. In addition, one interviewee was a specialist in one of Warsaw's housing cooperatives responsible for dealing with all formalities in the Warsaw City Hall. The length of the interviews ranged from $30 \mathrm{~min}$ to $6 \mathrm{~h}$. The interviews were recorded and subsequently transcribed.

Respondents were asked whether and what specific pathologies occur in the following areas: organisational solutions, social sphere, philosophy, values, strategy, relations with the environment and vertical and horizontal relationship. Methods of implementing change and reactions to change were discussed. An ancillary list, based on literature analysis, contained more than 30 examples of pathologies in these areas, but for the purpose of the research (creating an open catalogue of pathologies and dysfunctions), the researcher sought to avoid pointing out specific examples and suggestions to respondents. In addition, respondents were asked to indicate the manifestations and sources of the pathologies. Fulfilling the intended aim of the study and further work were not only meant to arrive at a better understanding of some of the phenomena taking place in organisations but also to serve a practical purpose to managers and entrepreneurs who are interested in the development of their organisations. They were meant to answer the questions - what not to do and how not to 
behave.

The use of partially structured interviews made it possible to acquire information that is both broad in nature and varied. However, the weak aspect of such research is the already mentioned lack of representativeness and limited possibilities for generalisation. In spite of the above-indicated difficulties and research limitations, a certain recurrence of opinions was achieved.

\section{Economic Downswings and Pathological Phenomena: Research Results}

The conducted research brings to the forefront a whole gamut of pathologies linked to unethical behaviour. As research conducted by PricewaterouseCoopers (2009) demonstrates the level of economic crime rises in times of crisis. The origins of such behaviour are to be found in the worsening economic situation of economic entities and, as it also seems, in poorly rooted moral standards as well as a lack of respect for the law on the part of many entrepreneurs and managers.

An important organisational problem that was pointed to by many participants in the study was unethical behaviour, including unethical leadership. The sources may be found in both the professed system of values and in the qualities of the employee as well as in organisational conditions, such as a high level of expectations on the part of the organisation, a high level of stress and forced behaviour through the operation of a hierarchy (Lecker, 2011, pp. 38-39). Actions forbidden by legal regulations (e.g. bribery and mobbing) and actions not unequivocally defined and forbidden (e.g. favouritism and preferential treatment in the private sector) are amongst the unethical activities that can be identified. The interviewed managers indicated that some of the specified phenomena, such as bribery or favouritism, increase in times of economic downswing whilst others, such as mobbing, have to ties to such downswings.

The conducted interviews demonstrated that during economic downswings, differences in perceiving organisational reality by various groups of participants are exacerbated. During a downswing, managers make decisions that, in their view, are rational. However, subordinates see them as unfair and injurious. Something that managers may consider as firmness is perceived by their subordinates (and often business partners) as ruthlessness. What owners or lenders view as a rationalising of operations may be just a reduction in jobs by workers. 'Economising' for some may be the 'shifting of duties' for others. The list goes on. Just about all participants in the study called attention to problems involving communications and difficulties in the proper presentation and justification of the need for change. Problems with communications are a universal phenomenon that occurs everywhere, regardless of the condition of the company. However, economic downswing is a factor revealing and exacerbating errors and organisational weaknesses.

An interesting question looked at by several interviewees was the concentration of excessive attention to cost control and cost cutting and the ignoring of pro-revenue actions during times of economic downswing. In a part of the organisations in which the interviewed managers were employed, a poor economic situation almost exclusively resulted in savings, where more often than not such savings related to areas and assets that could be considered as key company resources. Such actions give current benefits but, in the view of the interviewees, can limit the development potential of their organisation. A somewhat smaller group of interviewees indicated a growing disdain for making decisions in times of economic slump, which was most often explained by the managers' apprehension against losing their positions.

When indicating pathologies, most interviewees simultaneously sought their sources. Most often, the sources were 'objective factors' or 'factors independent of the managers'. It seems that downswings facilitate the perceiving of phenomena by becoming something of a catalyst for the rationalising of many (including one's own) improper behaviours and decisions.

Exceptional situations facilitate extreme behaviour and mistakes, whilst the increased dynamics in organisational behaviour underscores and intensifies the effects of all manners of organisational dysfunction. Some managers are aware of the fact that a poor economic situation coupled with pressure from stakeholders force the taking of decisions calculated for a very short time horizon, where any change in this state of affairs seems impossible. This is due to independent factors, 
principles of the free flow of capital and the enormous pressure (on the part of the media, regulators, shareholders, banks, etc.) for accelerating the dynamics of the functioning of the organisation.

Amongst the unfavourable phenomena facilitating organisational pathologies that intensify during a downswing, a fall in trust can also be observed. This pertains to not only the organisation's external relations, which are understandable in light of the increase in economic crime. As stressed by some study participants, people are the source of pathology and, in many cases, the "elimination of pathology will take place by replacing people'. Others noted a solution in the development of organisational information technology systems that can increase capabilities of monitoring workers whilst simultaneously limiting unconstrained freedom in actions by people occupying certain positions. Bearing in mind the systemic character of many dysfunctions, this signifies a tendency to seek out very simple and often deceptive solutions. At the same time, many managers stressed that they see the importance of trust and the building of an appropriate organisational culture.

Numerous errors, dysfunctions and pathologies may be the result of conscious and intentional decisions and organisational solutions. They may also be the effect of unconscious actions. Whether the error was committed consciously or unconsciously usually has no real meaning from the economic point of view. Its effects are losses, drops in efficiency, additional costs and other negative phenomena finding their reflection in the economic situation and social position of the organisation - waste. However, decisions and organisational actions face judgment by many stakeholders using diverse criteria. From the point of view of ethical principles, an unconscious managerial mistake resulting in a fall in company profits differs from a conscious decision causing the same decrease, but as the effect of corrupt actions. What is important is that those for whom, for obvious reasons, economic criteria are more important also use ethical criteria in their judgments. Thus, the media or even shareholders may 'forgive' a manager for his or her unconscious mistake in spite of the fact that it lead to tangible loses for the latter. A manager who caused the same problems as a result of conscious and dishonest actions cannot count on such lenience. However, sometimes the situation is more complex. Errors are conscious but unavoidable when they are the result of improper assumptions lying at the base of the organisation. A good and relatively common example illustrating this question is the selection of suppliers for a company. A significant part of companies (and almost all public sector institutions) are guided by the lowest delivery price in their selection. In spite of the best of intentions and many efforts on the part of the people responsible for supplies, the lowest price cannot always be reconciled with high quality, favourable payment deadlines, proper maintenance services and so on. Decisions regarding choice of one supplier over another are taken in a fully conscious manner, but from the point of view of the organisation, these decisions are not optimum. This is seen by not only the decisionmakers themselves but even by other stakeholders. However, such shape given to the decision is the result of improper assumptions functioning in the organisation or its surroundings and no one faults the decision-makers. In this case, organisational pathology involves the fact that everyone is aware of the decision being 'consciously improper', but the decision-maker had no choice and has to take it. Such error is committed consciously, but the decision-maker never had any intention of harming the organisation. The source of such errors lies in dysfunctional systemic assumptions.

\section{Final Comments and Conclusions}

A significant portion of pathologies indicated in this study comes down to the impossibility of taking fully rational decisions. This should not be a surprise because the term rationality itself is not sufficiently precise. It is derived from the Latin ratio, rationis, which means calculating, solving, reasoning and manner of thinking. In its turn, ratiocinatio means reasonable consideration. Simplifying somewhat, rational actions are actions based on reason. However, real rationality, translated into action rules, always takes place in defined historical, political, geographical, organisational, social and other conditions. These conditions are usually variable. Thus, speaking of fragmentary or limited rationality as well as of grading rationality is justified. What is valuable from the point of view of practice is Weber's statement that rationality reveals itself in the selection of the most effective (efficient) means to achieve previously defined goals (Kłosiński, 2000). However, it is possible to question both the rationality of selected goals as well as the selection of the most effective means itself (especially ex post). Differences in the assessment of rationality of actions from the 
perspective of the organisation as a whole and from the point of view of its selected parts are tied with a very severe organisational pathology - autonomisation.

Another problem is the contradiction between the rationality of a decision in the long and short terms. The same decision, whose implementation brings the desired effects, may play a role in the fostering of unfavourable phenomena and consequences in the long term. However, managers must take such decisions because if they do not, they will most probably not be able to serve their role for long. Subordinating decisions to short-term rationality becomes prerequisite to survival, but at the same time, it can have a negative impact on future development processes. Examples of such irrational behaviours may be indulging in fades and herd effects. What until recently was a standard worker responsibility presently becomes a 'project managed by the worker'. Outsourcing, lean management, reengineering and other methods of 'optimising costs' are applied almost universally and, more often than not, without any greater sense. The effect that this provides is often in the form of a short-lived improvement in financial results that, in the longer perspective, may lead to a situation in which the organisation has no surplus that can make possible the starting up of new processes.

In presuming that the currently dominant assumption that the goal of the organisation is survival and development, decisions leading to the maximising of short-term benefits at the cost of the future should be considered a pathology. However, it cannot be ruled out that as a result of a changing reality, not only the organisational lifecycle will shorten but basic assumptions regarding organisational targets will also be subject to revaluation.

The sources of pathologies are systemic and complex. This also means that there are no universal solutions for these problems. However, there exist more or less effective fragmentary solutions. In essence, management would not have been isolated as an area of interest of practitioners and theoreticians, a subject of numerous studies and ultimately a scientific discipline if not for having the experience numerous problems linked with the functioning of the organisation. Amongst other reasons, these problems were the effect of recurring errors and irregularities in managing. Just about all authors have formulated guidelines for ancient and modern managers alike, warning against the committing of such errors. In writing how to proceed, they simultaneously called attention to what not to do.

There continues to be a need for such guidelines today. In the view of Gestmann (2001), 'in moments of despair, entrepreneurs reach for every, even semi-credible theory relating to management. All known principles of management, from Total Quality Control, through Human Relations, to Reengineering, are instructions that promise help in eliminating organizational, communication, dependency-based, and other interference found in the workplace without actually studying just what the reasons are in an exhaustive manner'. A downswing in the economy exposes and, to a certain extent, intensifies pathological phenomena. On the other hand, it is a period of searching and creating new solutions and instruments in the area of management. Expectations relating to the identification and elimination of the most visible and greatest pathologies are growing. The intended goal: creating an 'open catalogue of pathologies and dysfunctions' by definition requires the continuation of research. Its theoretical and practical significance will grow as the number of respondents and the scope of the study on the causes and sources of pathology increase. This can also lead to creating an outline of an early warning system for the most common dysfunctions and pathologies in organisation.

\section{References}

Albrecht K. (2003). The Power of Minds at Work: Organizational Intelligence in Action, New York: American Management Association

Archer D. (1999). Exploring "Bullying" Culture in Para-Military Organisations. International Journal of Manpower, Vol. 20, N. 1-2, pp. 94-105.

Ashforth B. (1984). Petty Tyranny in Organizations. Human Relations, Vol. 47, No. 7, pp. 755-778

Awa W. L., Plaumann, and Walter U. (2010). Burnout Prevention: A Review of Intervention Programs. Patient Education and Counseling, Vol. 78, No. 2, pp. 184-190. 
Björkvist K., Österman K., and Hjelt-Bäck M. (1994). Aggression among University Employees. Aggressive Behavior, Vol. 22, No. 3, pp. 173-184

Bogle J. C. (2009). Dość [Enough], Warsaw: PTE.

Brown P., Hesketh A. (2004) The Mismanagement of Talent. Employability and Jobs in the Knowledge Economy. Oxford: Oxford University Press.

Cameron K.S., Whetten D.A., Kim M.U. (1987) Organizational Dysfunctions of Decline. The Academy of Management Journal, Vol. 30, No 1, pp. 126-138

Chan D. W. (2011). Burnout and Life Satisfaction: Does Gratitude Intervention Make a Difference among Chinese School Teachers in Honk Kong? Educational Psychology, Vol. 31, No. 7, pp. 809-823.

Christensen J.G. (1993) Corporatism. Administrative Regimes and the Mis-management of Public Funds. Scandinavian Political Studies, Vol. 13, No. 3. pp. 201-224.

Dobrzyński M. (2012). Doktryna szoku jako inspiracja współczesnego zarzązania [The doctrine of shock as inspiration for modern management]. Warsaw: University of Warsaw Scientific Press.

Einarsen S. (2000). Harassment and Bullying at Work: A Review of the Scandinavian Approach. Aggression and Violent Behavior, Vol. 5, No. 4, pp. 16-27.

Fink G., Dauber D., and Yolles M. (2012) Understanding Organizational Culture as a Trait Theory. European Journal of International Management, Vol. 6, Issue 2, pp. 199-220.

Gestmann M. (2001). Sabotaż w miejscu pracy [Sabotage in the workplace]. Cracow: Professional Business School Press.

Goffnett S. P, Lepisto L., and Hayes R. (2016). Using the Socio-Economic Approach to Management to Augment Lean SiX Sigma. International Journal of Productivity and Performance Management, Vol. 65, Issue 1, pp. 80-97.

Gouliemos M. (2005). Applying the Organizational Failure Diagnosis Model to the Study of Information Systems Failure. Disaster Prevention Management, Vol. 14, Issue 3, pp. 362-377.

Guy M. (1989). From Organizational Decline to Organizational Renewal: The Phoenix Syndrome. New York: Quorum Books.

Halbesleben J. R. B., Osburn H. K., and Mumford M. B. (2006). Action Research as a Burnout Intervention: Reducing Burnout in the Federal Service. Journal of Applied Behavioral Science, Vol. 42, No. 2, pp. $244-266$.

Heller V.L, Darling J.R (2011) Toyota in crisis: denial and mismanagement. Journal of Business Strategy, Vol. 32 Issue: 5, pp.4-13.

Kets de Vries M. F. and Miller D. (1984). Neurotic Style and Organizational Pathology, Strategic Management, Vol. 5, Issue 1, pp. 35-55.

Kieżun W. (1971). Autonomizacja jednostek organizacyjnych. Z patologii organizacji [The autonomization of organizational units: Organizational pathology]. Warsaw: PWE.

Kieżun W. (2012). Patologia transformacji [Transformation pathology]. Warsaw: Poltext sp. z o. o.

Kłosiński K. (2000). Racjonalność w procesach społeczno-gospodarczych [Rationality in social and economic processes]. In Racjonalność myślenia, decydowanie $i$ działanie [Rational thought, deciding, and acting], L. W. Zacher (Editor). Warsaw: Koźmiński University, pp. 66-70.

Launsby R. G. (2016) Medical Device Challenges. Launsby Consulting, Available from Internet: http://www.launsby. com/Articles/MedDeviceChallenges.pdf, [accessed on June 29, 2016].

Lecker M. J. (2011). When Corporate Leaders Behave Badly. Human Resource Management. Polish Academy of Sciences and Institute of Labor and Social Studies 6/2011 (83), pp. 38-49.

Lencioni P. (2005). Pięć dysfunkcji pracy zespołowej [Five dysfunctions in teamwork]. Konstancin-Jeziorna: MT Biznes.

McMillan C. and Overall J (2016). Wicked Problems: Turning Strategic Management Upside Down. Journal of Business Strategy, Vol. 37, Issue 1, pp. 34-43.

Miller D. (1988). Organizational Pathology and Industrial Crisis, Organization \& Environment, Vol. 2, Issue 1, pp. 65-74. 
Miller J. G. and Miller J. L. (1991), A Living System Analysis of Organizational Pathology. Behavioral Science, Vol. 36, Issue 4, pp. 239-252.

Pasieczny J. (2005) Dlaczego kryzys nie musi prowadzić do rozwoju [Why crisis does not have to lead to development]. Przegląd Organizacji [Organizational Overview] 6/2005, pp. 7-11.

Pasieczny J. and Glinka B. (2008). Błędy menedżerskie - wybrane źródła i implikacje dla rozwoju organizacji [Managerial mistakes: Selected sources and implications for the development of organizations]. Problemy Zarządzania [Management Issues] 4/2008 (22), pp. 153-166.

Perlow L. A., Okhuysen G. A., and Repenning N. P. (2002). The Speed Trap: Exploring the Relationship between Decision Making and Temporal Context. Academy of Management Journal, Vol. 45, Issue 5, pp. 931955.

Petrucelli J.R., Peters J.R (2017) Preventing Fraud and Mismanagement in Government: Systems and Structures. Hoboken N.J: John Wiley \& Sons Inc.

PWC, (2012) Presja gospodarcza prowadzi do częstszego występowania przestęstw gospodarczych [Economic pressure leads to more frequent economic crime]. Available from Internet: http://www.pwc.pl/pl/biuroprasowe/presja-gospodarcza-prowadzi-do-czestszego-wystepowania-przestepstw-gospodarczych.jhtml. [accessed on June 21, 2012].

Robinson S. L. and Bennett R. J. (1995). A Typology of Deviant Workplace Behaviors: A Multidimensional Scaling Study. Academy of Management Journal, Vol. 38, Issue 2, pp. 555-572.

Samuel Y. (2010). Organizational Pathology: Life and Death of Organizations. New Brunswick: Transaction Publishers.

Schulman P. R. (1989). The Logic of Organizational Irrationality. Administration \& Society, Vol. 21, Issue 1, pp. $31-53$.

Scott W. R. (1992). Organizations: Rational, Natural and Open Systems. Englewood Cliffs, New Jersey: Prentice-Hall.

Simon H. A. (2007). Podejmowanie decyzji i zarządzanie ludźmi w biznesie $i$ administracji [Taking decisions and managing people in business and administration]. Gliwice: Helion.

Stocki R. (2005). Patologie organizacyjne - diagnoza i interwencje [Organizational pathologies: Diagnosis and intervention]. Cracow: Oficyna Ekonomiczna.

Webb J. (1992) The Mismanagement of Innovation. Sociology, Vol. 26, No. 3. pp. 471-492.

White R. D. (2010). The Micromanagement Disease: Symptoms, Diagnosis and Cure. Public Personnel Management, Vol. 39, Issue 1, pp. 71-76. 